Mora M., Marx Gómez J., O’Connor R.V., Meyendriesch B. (2017) ITSDM: A Methodology for IT Services Design. In: Marx Gómez J., Mora M., Raisinghani M., Nebel W., O'Connor R. (eds) Engineering and Management of Data Centers. Service Science: Research and Innovations in the Service Economy. Springer, Cham.

\title{
ITSDM: A Methodology for IT Services Design
}

\author{
Manuel Mora ${ }^{1}$, Jorge Marx Gómez ${ }^{2}$, Rory V. O'Connor ${ }^{3}$ and Burkard Meyendriesch ${ }^{4}$ \\ ${ }^{1}$ Department of Information Systems, Autonomous University of Aguascalientes, Aguascalientes, Mexico, 20000, e-mail: \\ mmora@securenym.net \\ 2 Department of Informatics, Carl von Ossietzky University Oldenburg, Oldenburg, Germany, 26129, e-mail: \\ jorge.marx.gomez@uni-oldenburg.de \\ ${ }^{3}$ School of Computing, Dublin City University, Glasnevin, Dublin, Ireland, 9, e-mail: rory.oconnor@dcu.ie \\ ${ }^{4}$ IT Services Department, Carl von Ossietzky University Oldenburg, Oldenburg, Germany, 26129, e-mail: \\ burkard.meyendriesch@uni-oldenburg.de
}

\begin{abstract}
The main international Information Technology Service Management (ITSM) process frameworks such as ITIL V3 and the ISO/IEC 20000-4, includes a service design process as part of their mandatory set of processes. Nevertheless, even with such availability of processes, their used nomenclature, their phase-activity structure, and their granularity level used for their descriptions, are non-standardized. Consequently ITSM academics are faced with a useful but disparate and diffused literature, and ITSM professionals lack of a suitable step-by-step service design methodologies. In this chapter, we present ITSDM (Information Technology Service Design Methodology), which is elaborated on best practices suggested in ISO/IEC 20000-4 and ITIL v3 design processes with the aim to provide a step-by-step guideline with phases, activities, tasks, roles, controls and input-output artifacts. We illustrate its utilization with a real IT service (Cloud Storage service) that is ready operational in a German Higher Education Institution. We found that ITSDM provided qualitative benefits such as: ease of use, usefulness, compatibility and value. However, given the novelty of this methodology, we encourage for further empirical studies for providing more definitive results.
\end{abstract}

\section{Keywords}

IT service, service design, ISO/IEC 20000-4, ITIL v3, service science

\section{Introduction}

IT Service Management (ITSM) refers to a management system of organizational resources and capabilities for providing value to organizational customers through IT services (van Bon et al., 2010). ITSM has become a relevant organizational theme for IT areas in large and mid-sized organizations because it is expected that its utilization, jointly with other IT schemes of processes, deliver a more efficient and effective IT management, and ultimately a better organizational value (Johnson et al. 2007; Gallup et al. 2009). Studies on ITSM impacts (Hochstein et al. 2005; Cater-Steel and Toleman 2006; Potgetier et al. 2006; Cater-Steel et al. 2009) report evi- 
dence of positive impacts. Among the main benefits include: a better client/service orientation, a better quality of IT services, a better efficiency of IT processes, and a better visibility on transparency and comparability documentary issues, a more consistent and documented service management process (less negative surprises or omissions), less conflictive SLAs negotiations (smoother), more precise predictions of IT infrastructure warranty issues, and a better management of incidents, changes and testing tasks.

However, to obtain such benefits demand that ITSM practitioners - and their organizations- must firstly to select, learn, and deploy an ITSM process framework such as: ISO/IEC 20000 (ISO 2005; 2010) and ITIL V3 (Cartlidge 2007; van Bon et al. 2010). In this chapter, we are interested in the IT service design process. We consider that for ITSM practitioners and academicians this IT service design implies practically a new problem demanding the adaptation/enhancement of usual software systems development methodologies. The design of an IT service is more complex in general than the design of a software system because an IT service involves several components (hardware, software, DBMS, networks, data, applications, environment, and internal and external teams). Furthermore, few comparative studies on IT service design process have been reported in the literature (Mora et al. 2012; 2014; 2015). Consequently, IT service design processes emerge as a relevant current research problem (Ebert et al. 2007; Weist 2009; Mora et al. 2011; 2012).

In this chapter, we address such a real and academic problematic situation on the lack of a step-by-step service design methodology, and present ITSDM (Information Technology Service Design Methodology), which is elaborated on best practices suggested in ISO/IEC 20000-4 and ITIL v3 design processes. ITSDM provides a step-by-step guideline with phases, activities, tasks, roles, controls and input-output artifacts. We illustrate its utilization with a real IT service (Cloud Storage service) that is ready operational in a German Higher Education Institution. We found that ITSDM pro-vided qualitative benefits such as: ease of use, usefulness, compatibility and value. ITSDM was designed through a formulative-evaluative conceptual design research method (Glass et al. 2004; Hevner et al. 2004; Mora et al. 2008).

The remainder of this chapter continues as follows: in Section 2 we describe the research method. In section 3 , we review the related work on service design process reported in ITIL v3 and ISO/IEC 20000-4:2010. In Section 4 we report the conceptual design and validation of ITSDM. We end this chapter, in Section 5 with contributions, limitations and conclusions

\section{Background and Research Approach}

The concepts of service and IT service have been defined in different modes by the most recognized ITSM processes frameworks (Mora et al. 2014). In ITIL V3 (OGC, 2007), a service is defined, as a means of delivering value to customers by facilitating outcomes customers want to achieve without the ownership of specific costs and risks. An IT service is defined as a service provided to one or more customers by an IT service provider, based on the use of IT and supports the customer's business processes, and is made up from a combination of people, processes and technology and defined in a Service Level Agreement. In ISO/IEC 20000 standard (ISO, 2005), the concepts of service and IT service are used implicitly. In ISO 9000:2005 (ISO, 2005), a service is an intangible resultant from the interaction of activities between a supplier and a customer.

Design - as a research paradigm- is a prescriptive mode for advancing the performance of systems. In contrast with a knowledge-producing descriptive mode -which pursues to understand their natural behavioral of used systems-, design is a knowledge-using activity pursued for developing useful systems (i.e. IT systems in particular in this studied context) (March and Smith 1995). Design is about "devising artifacts to attain goals" (idem, p. 253). Design products are assessed usually using utility or value criteria. Two core activities in design are build and evaluate. "Building is the process of constructing an artifact for a specific purpose; evaluation is 
the process of determining how well the artifact performs" (idem, p. 254). Design -as a substantive- is the generated artifact from design activity. It can be classified either: construct, model, method or implementation.

An IT service must be carefully planned and designed in order to be built as expected. An informal design process cannot establish performance, risk-based, security and cost-effective guarantees to users. Designing IT services helps mainly to avoid costly disruptions in operational settings caused by design flaws, and to produce expected performances. A high quality design implies to achieve it into the design space caused by the application of constrains (usually bounds on available resources) rather attaining the maximum or minimums values without consideration to the attached design constrains.

In ITIL V3 (Rudd and Llyod 2007), service design is the core process of gathering service needs and mapping them to requirements for integrated services, and creating the design specifications for the service assets needed to provide services. In ISO/IEC 20000-4:2010 (ISO, 2010), two of the four new processes are linked to service design activities: service requirements where the service needs are established and agreed, and service design where the new or changed service is designed and developed.

Hence, we can refer in general to systems design as a verb and as the intellectual activity to transform a set of system requirements in a set of system specifications which satisfy a set of agreed goals and constrains which will enable the development and building of the designed system. Agreed goals are expected properties for system users (usually related with performance, security, and usability issues), while that agreed constrains are limits (minimums, maximums, or ranges) on characteristics of the design process per se (usually related with the consumption of time-based, financial, organizational, materials, and other related resources used for design, building and operating the expected system). In turn, system design can be defined as the conceptual artifact, which conveys a set of system specifications which enable its further development and building with assumed and extant design resources.

Service design is thus a relevant process for ITSM process frameworks. However, while that the two main international ITSM process frameworks (ITIL V3 and the ISO/IEC 20000-4) include a service design process as part of their mandatory set of processes, their used nomenclature, their phase-activity structure, and their granularity level used for their descriptions, are non-standardized (Mora et al. 2014; 2015). Consequently, ITSM academics are faced with a useful but disparate and disperse literature, and ITSM professionals lack of step-by-step service design methodologies.

ITSDM was designed through a formulative-evaluative conceptual design research method (Glass et. al. 2004). March and Smith (1995) indicate that a design research approach can be used to build and evaluate nontrivial, non-naturally created and non-existent artifacts needed for human-being purposes. In design research, a build activity responds to the inquiry: is it feasible to build an artifact $\mathrm{X}$ by using a method, materials, and tools $\mathrm{Y}$ ? and an evaluation activity to the inquiry: does the artifact $\mathrm{X}$ fulfill the design range of a set of expected metrics? While March and Smith (1995) does not report guidelines for the build activity, they suggest two critical metrics for the evaluation activity: utility and value, in contrast to truthiness for natural and behavioral sciences. Design research method has been also enhanced by Hevner et al. (2004) guidelines. In Hevner et al.'s framework (2004), seven design research guidelines) and four types of products (design artifacts: constructs, models, methods, or instantiations) are proposed. These recommendations were followed.

A formulative-evaluative conceptual design research method (extended by Mora et al. 2008) was used with five activities as follows: 1) Knowledge Gap Identification, 2) Methodological Knowledge Selection, 3) Conceptual Design, 4) Design Data Collecting, and 5) Analysis and Synthesis. Activities 1) and 2) corresponds to section 3 of this chapter. Activities 3), 4) and 5) are reported in section 4. 


\section{Theoretical Background on IT Service Design Processes}

The design of IT services is based essentially on an IT service architecture design model. This model can be defined as a conceptual representation of a service system, which reports its essential components and interrelationships in an organized and hierarchical mode (Maier et al. 2004; Mora et al. 2014). Modeling IT service architectures can be pursued for several purposes: facilitate human understanding of IT service systems, support IT service systems management, support IT service systems improvement, automate IT service systems guidance and enact automated IT service systems (Curtis et al. 1992; Maier et al. 2004). Given the novelty of IT service systems and the variety of IT service process frameworks, there are also a dispersion of IT service architecture design models. Consequently, IT service academics and practitioners face a fragmented and nonstandardized view of what is an IT service architecture design model.

In ITIL v3 (Rudd and Lloyd, 2007), the concept of IT service architecture model is reported as a Service Composition Diagram and a Service Relationship-Dependence Model. In Fig. 1 we report an adaptation of both diagrams (Mora et al. 2014).

The core elements derived from both diagrams are the following: (i) business unit, (ii) business service, (iii) business process, (iv) IT service (service utility, service warranty (SLAs)), (v) assets/resources (infrastructure (HW, SW, DBMS, NW), environment, data, applications), and (vi) assets/capabilities (IT processes, support teams (OLAs), suppliers (UCs)). The derived interrelationships are the following: R1 a business unit delivers business services; R2 a business service is made up of business processes; R3 business processes (and lately business services) are supported by IT services; R4 an IT service is characterized by service utility and warranty parameters; R5 an IT service is made up of assets/resources and assets/capabilities; R6 assets/resources are infrastructure (HW, SW, DBMS, NW), environment, data, and applications; R7 assets/capabilities are IT processes, support teams and suppliers. 


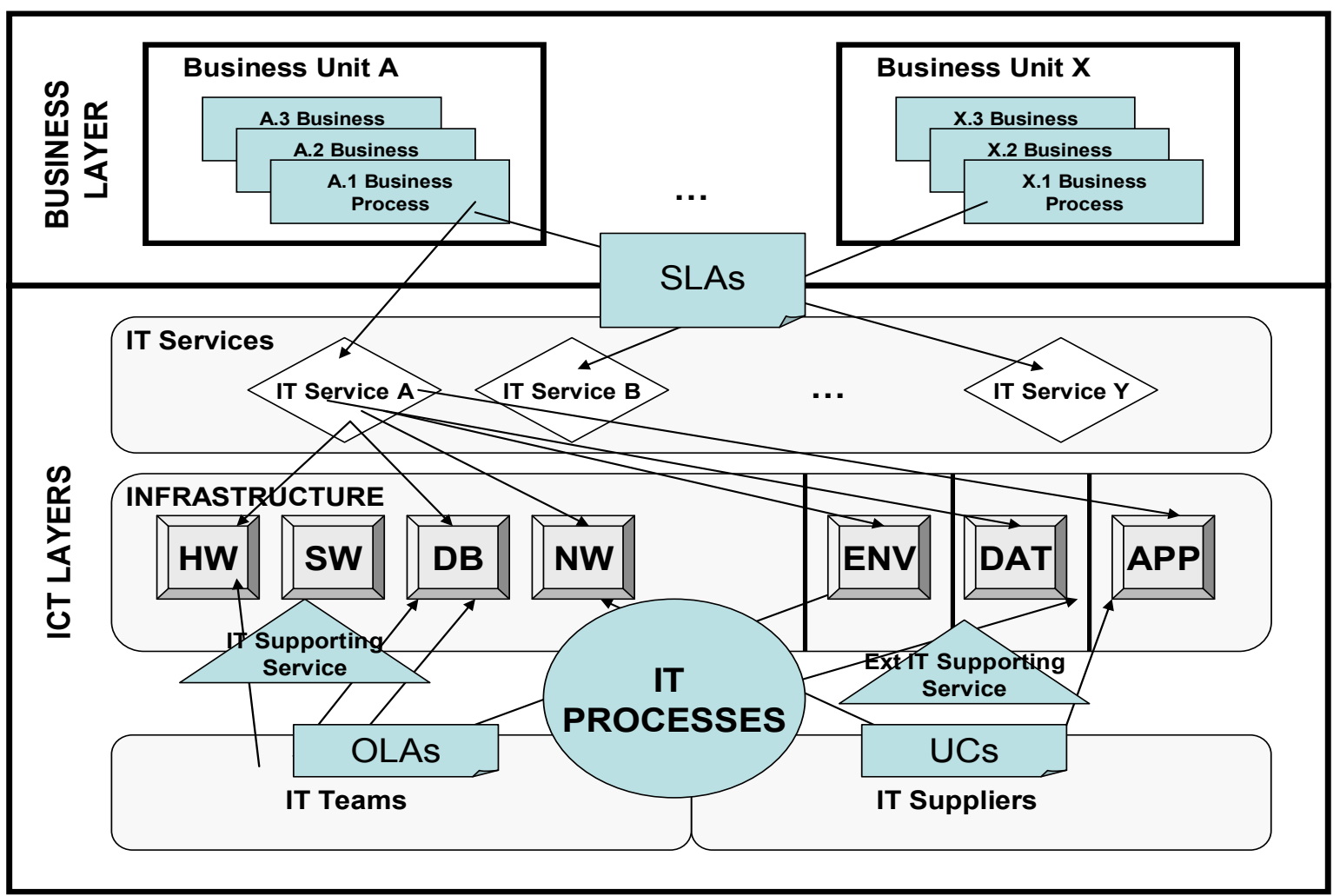

Fig. 1 ITIL v3 Service Composition Model and Service Relationship-Dependence Model

\begin{tabular}{|c|c|c|c|c|c|}
\hline \multicolumn{6}{|c|}{ Organization $\mathrm{X}$} \\
\hline \multicolumn{6}{|c|}{ Customer Y - Business Units Layer } \\
\hline \multicolumn{6}{|c|}{ IT Services Layer } \\
\hline \multicolumn{6}{|c|}{ IT Internal Service Provider Layer } \\
\hline & \multicolumn{5}{|c|}{ Technology / Infrastructure and Service Components } \\
\hline $\begin{array}{c}\text { External } \\
\text { IT } \\
\text { Service }\end{array}$ & $\begin{array}{c}\text { Servers, } \\
\text { mainframes, } \\
\text { desktops, } \\
\text { storage } \\
\text { systems, }\end{array}$ & $\begin{array}{c}\text { Networks, } \\
\text { telecommunications, } \\
\text { mobile and smart } \\
\text { devices }\end{array}$ & $\begin{array}{c}\text { Application } \\
\mathrm{s}\end{array}$ & $\begin{array}{c}\text { Managemen } \\
\text { t tools and } \\
\text { systems }\end{array}$ & $\begin{array}{c}\text { Environmental } \\
\text { systems }\end{array}$ \\
\hline $\begin{array}{c}\text { External } \\
\text { Service } \\
\text { Provider }\end{array}$ & \multicolumn{5}{|c|}{ IT Service Suppliers Layer } \\
\hline
\end{tabular}

Fig. 2 ISO/IEC 20000 IT Service Architecture Design Model

In ISO/IEC 20000 (ISO, 2005; 2010) there is no IT service architecture design model reported explicitly. However, it can be derived one from several insights. Fig. 2 illustrates the derived IT service architecture model. In this model, the core-identified entities are: (i) an organization, (ii) a customer, (iii) business units, (iv) IT ser- 
vices, (v) IT internal or external service provider, (vi) technology (hardware, network, applications, systems, and environmental systems), (vii) external service provider, and (viii) suppliers. The derived interrelationships are the following: R1 an organization has customers; R2 customers have one or several business units; R3 business units use IT services; R4 the IT services are delivered by IT internal or external service providers; R5 the IT internal service provider uses technology; R6 the technology is acquired from suppliers.

In ITIL v3 (Rudd and Llyod, 2007), there is a full phase devoted to the service design process. This fact suggests the relevance of design activities for fulfilling the expected quality of service levels to be delivered. In this service design phase are included the following processes: Service Catalog Management, Service Level Management, Capacity Management, Availability Management, IT Service Continuity Management, Information Security Management, and Supplier Management. Interesting to be identified, is the non-explicit definition of a step-by-step service design process per se.

In contrast, in ITIL v3, five dimensions of service design to be considered and included in an IT service design are proposed: Services, Design of Service Management systems and tools, Technology architectures and management systems, Processes, and Measurement methods and metrics. However, ITIL v3 reports a set of activities that grouped pursue a design goal. These are not presented as an integrated process, but they can be identified as follows: (i) Identifying service requirements, (ii) Identifying and documenting business requirements and drivers, (iii) Designing and Risk Assessment, (iv) Evaluation of alternative solutions, (v) Procurement of the preferred solution, and (vi) Develop the service solution.

In ITIL v3 the role of service design is established as: 'The design of appropriate and innovative IT services, including their architectures, processes, policies and documentation, to meet current and future agreed business requirements". Service design must consider the following elements in ITIL v3: business process to be supported, the service itself, SLAs/SLRs, Infrastructure (all of the IT equipment necessary to deliver the service to the customers and users), Environment (the environment required to secure and operate the infrastructure), Data, Applications, Support Services, Operational Level Agreements (OLAs) and contracts: any underpinning agreements necessary to deliver them, Support Teams, and Suppliers.

The IT service design process in ISO/IEC 20000 appears in the ISO/IEC 20000-4:2010 (ISO, 2010). In the three first parts of the ISO/IEC 20000 (ISO, 2005) documents, derived from ITIL v2 mainly, does not report on an explicit IT service design phase or process. However, in the new documents, two of the four new processes reported are linked to service design activities. This new category is called Design and Transition of New or Changes Services, and the two linked processes are: Service Requirements, and Service Design.

In Service Requirements, the service requirements are established and agreed. The service may be asked from the Service Catalogue (build for catalogue mode) or as totally new services (build to order mode). Five products are expected of this process: required characteristics and context of service, constraints for a service solution, service requirements, validation of such service requirements, and a set of final agreed and negotiated implemented requirements.

In Service Design, the new or changed service is designed and developed. This process must generate an agreed solution including the service itself and service components. The design must guarantee that the agreed service requirements be satisfied. Four products are expected from this process: a new or changed service design which meets business needs and service requirements, a service specification, a detailed list of infrastructure and service components to support the designed service, and the development of the designed service.

Similarly to ITIL v2, in ISO/IEC 20000 additional processes are partially linked for this service design aim: Service Level Management (SLM), Release Management (RM), and Configuration Management (CM). In SLM the need of defining a service catalogue and service level agreements implies service design activities to be fulfilled. In RM, a final release package must be designed, build and configured. In turn, in CM all technical information of the configuration items (e.g. their components, physical, and logical interrelationships) must be documented. 
The Table 1 shows a summary of the core process-activities, roles and related processes of service design in ITIL v3 and ISO/IEC 20000.

In order to assess the extent of support provided by these service design processes in ITIL V3 and ISO/IEC 20000, adapted from Mora et al. (2015), we use a process framework from the systems engineering area: the ISO/IEC 15288 standard (ISO, 2007). The ISO/IEC 15288 standard contains 4 process categories: Enterprise, Project, Technical and Agreement. System engineering is a discipline defined as "an interdisciplinary approach and means to enable the realization of successful (cost-efficient and trustworthy) systems" (Sage, 2000; INCOSE, 2004). For the systems engineering discipline, a system is "an integrated set of elements that accomplish a defined objective. These elements include products (hardware, software, firmware), processes, people, information, techniques, facilities, services, and other support elements." (INCOSE, 2004). We consider this conceptualization of a system covers adequately the concept of IT service, and thus the ISO/IEC 15288 process standard provides a suitable assessment framework.

Table 1 A Summary of ITIL v3 and ISO/IEC 20000 Service Design Processes

\begin{tabular}{|c|c|c|}
\hline $\begin{array}{l}\text { Service Core Design } \\
\text { Process and Activities }\end{array}$ & Service Design Roles & $\begin{array}{c}\text { Service Design } \\
\text { Related Activities }\end{array}$ \\
\hline $\begin{array}{l}\text { ITIL V3: } \\
\text { IMPLICIT SERVICE DESIGN (in } \\
\text { Service Design Package): } \\
\text { A1. Identifying service requirements. } \\
\text { A2. Identifying and documenting } \\
\text { business requirements and drivers. } \\
\text { A3. Designing and Risk Assessment. } \\
\text { A4. Evaluation of alternative solu- } \\
\text { tions. } \\
\text { A5. Procurement of the preferred so- } \\
\text { lution. } \\
\text { A6. Develop the service solution. }\end{array}$ & $\begin{array}{l}\text { ITIL V3: } \\
\text { 1. Service Design Manager. } \\
\text { 2. IT Designer/Architect. } \\
\text { 3. Service Design Process } \\
\text { Managers. } \\
\text { 4. Customer. } \\
\text { 5. User. }\end{array}$ & $\begin{array}{l}\text { ITIL V3: } \\
\text { Serv. Catalogue Mgt. } \\
\text { Serv. Level Mgt. } \\
\text { Capacity Mgt. } \\
\text { Availability Mgt. } \\
\text { IT Serv. Continuity Mgt. } \\
\text { Information Security Mgt. } \\
\text { Supplier Mgt. }\end{array}$ \\
\hline $\begin{array}{l}\text { ISO/IEC 20000: } \\
\text { SERVICE REQUIREMENTS: } \\
\text { A1. Identification of required charac- } \\
\text { teristics and context of service. } \\
\text { A2. Identification of constraints for a } \\
\text { service solution. } \\
\text { A3. Elicitation of service require- } \\
\text { ments. } \\
\text { A4. Validation of service require- } \\
\text { ments. } \\
\text { A5. Agreement of final implementa- } \\
\text { ble requirements. } \\
\text { SERVICE DESIGN: } \\
\text { A1. General Design of a new or } \\
\text { changed service design. }\end{array}$ & $\begin{array}{l}\text { ISO/IEC 20000: } \\
\text { 1. Service Design Team. } \\
\text { Related Roles: } \\
\text { 1. Release Manager. } \\
\text { 2. Service Level Manager. } \\
\text { 3. Configuration Manager. }\end{array}$ & $\begin{array}{l}\text { ISO/IEC 20000: } \\
\text { Serv. Level Mgt. } \\
\text { Release Mgt. } \\
\text { Configuration Mgt. } \\
\text { Serv. Planning and Moni- } \\
\text { toring }\end{array}$ \\
\hline
\end{tabular}



A2. Specification of service.
A3. Identification of detailed list of infrastructure and service compo- nents.
A4. Development of the designed service.

The ISO/IEC 15288 standard (ISO, 2007) contains 4 process categories: Enterprise, Project, Technical and Agreement. Each one includes respectively 5, 7, 11 and 2 processes, as illustrated in figure 3. In our analysis of the IT service design process for ITILV3 and ISO/IEC 20000 we included only the most related processes with a system design purpose.
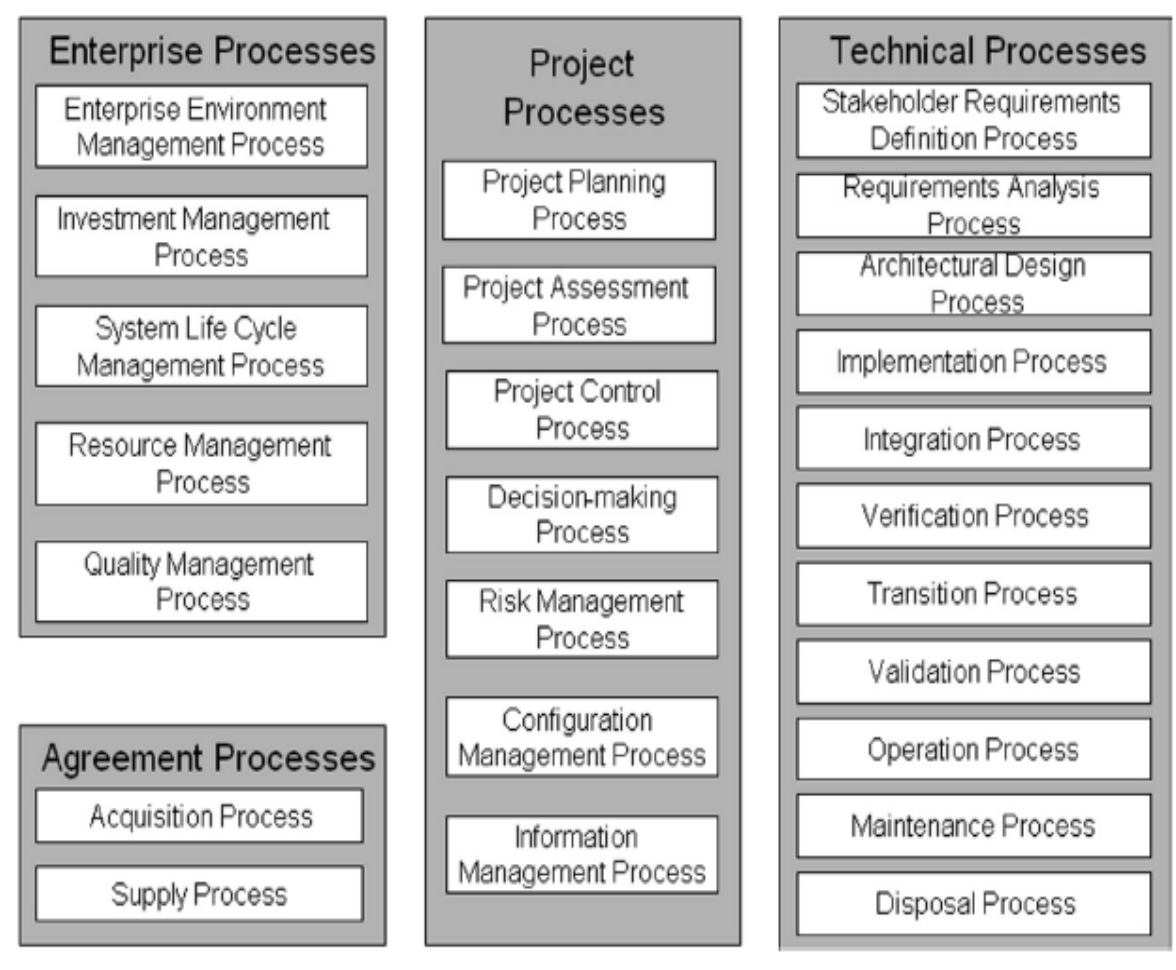

Fig. 3 ISO/IEC 15288 Standard from Systems Engineering

However, given the disparity of views in the two ITSM schemes we consider useful to establish three essential categories of purpose as follows: planning-control, analysis-design, and build-transition. Using this categorization, we were able to select the most related design processes from the four ISO/IEC 15288 process categories to be used as the normative comparative particular model. These selected processes were the following: acquisition and supply processes (from Agreement category); project planning, project control, decision-making, and risk management (from Project category); and stakeholder requirements definition, requirement analysis, architectural design, implementation, integration, verification, transition and validation processes (from Technical 
category). The Table 2 shows a summary of the service design process evaluation of ITIL v3 and ISO/IEC 20000.

In the Table 3, adapted from Mora et al. (2015) we show a summary of three analyzed issues (foundational concepts of IT services, IT service design architecture layers, and design processes). We found that ITIL v3 has a strong to moderate assessment. In contrast the ISO/IEC 20000 standard was found as moderate to weak, due to the scarce information provided by the consulted documents. As instance, the design process is reported in a text about 450 words.

Table 2 Assessment of IT Service Design (and most related) Process reported in ITIL v3 and ISO/IEC 20000 from a Systems Engineering view

\begin{tabular}{|c|c|c|}
\hline $\begin{array}{l}\text { SYSTEMS ENGINEERING ISO/IEC } 15288 \text { PROCESSES } \\
\text { STANDARD }\end{array}$ & $\begin{array}{c}\text { ITIL } \\
\text { V3 }\end{array}$ & $\begin{array}{l}\text { ISO/IEC } \\
20000\end{array}$ \\
\hline PLANNING-CONTROL PROJECT PROCESSES & STRONG & STRONG \\
\hline Acquisition / Supply processes & STRONG & STRONG \\
\hline Project planning / Project control processes & STRONG & STRONG \\
\hline Decision-making / Risk management processes & STRONG & STRONG \\
\hline ANALYSIS-DESIGN PROCESSES & MODERATE & MODERATE \\
\hline Stakeholder requirements definition & STRONG & STRONG \\
\hline Requirements analysis & STRONG & STRONG \\
\hline Architectural design & WEAK & WEAK \\
\hline BUILD-TRANSITION PROCESSES & STRONG & STRONG \\
\hline Implementation / Integration processes & STRONG & STRONG \\
\hline Verification & STRONG & STRONG \\
\hline Transition & STRONG & STRONG \\
\hline Validation & STRONG & STRONG \\
\hline $\begin{array}{l}\text { OVERALL EVALUATION REGARDING THE SUPPORT } \\
\text { PROVISIONED TO IT SERVICE DESIGN PURPOSE }\end{array}$ & MODERATE & MODERATE \\
\hline
\end{tabular}

Table 3 Synthesis of Findings on ITIL V3 and ISO/IEC 20000 regarding their IT Service Design Processes

\begin{tabular}{lcc}
\hline \multicolumn{1}{c}{ ANALYZED ISSUE } & ITIL V3 & ISO/IEC 20000 \\
\hline Foundational concepts (service, IT service) & MODERATE & MODERATE \\
IT service design architecture layers & STRONG & WEAK \\
Design processes & MODERATE & MODERATE \\
OVERALL EVALUATION & MODERATE & WEAK \\
\hline
\end{tabular}

Hence, we claim that while these two main international ITSM process frameworks include a service design process as part of their mandatory set of processes, their used nomenclature, their phase-activity structure, and their granularity level used for their descriptions, are non-standardized. Consequently, ITSM academics are faced with a useful but disparate and disperse literature, and ITSM professionals lack of step-by-step service design methodologies. 


\section{The IT Service Design Methodology: Description and Illustrative Case}

\subsection{ITSDM Description}

ITSDM can be considered an enhancement of the general recommendations reported in ISO/IEC 20000 and as a condensed step-by-step methodology derived from ITIL V3 processes for designing IT services.

The purpose of ITSDM is to provide a systematic and well-defined methodology -based on best practices suggested in ISO/IEC 20000 and ITIL V3 design processes- for designing IT services in medium-sized Datacenters environments.

ITSDM consists of three phases: 1) IT service requirements analysis, 2) IT service core design, and 3) IT service operation-monitoring-rskmgt planning. The figure 4 shows an IDEF0 diagram of the overall process. An IDEF0 diagram (Mayer 1992; Presley and Liles 1995) includes the activities, inputs, outputs, controls and mechanisms (i.e. roles). The IDEF0 diagrams have been widely used for elaborating well-structured process descriptions (Mayer 1992; Presley and Liles 1995) in several domains.

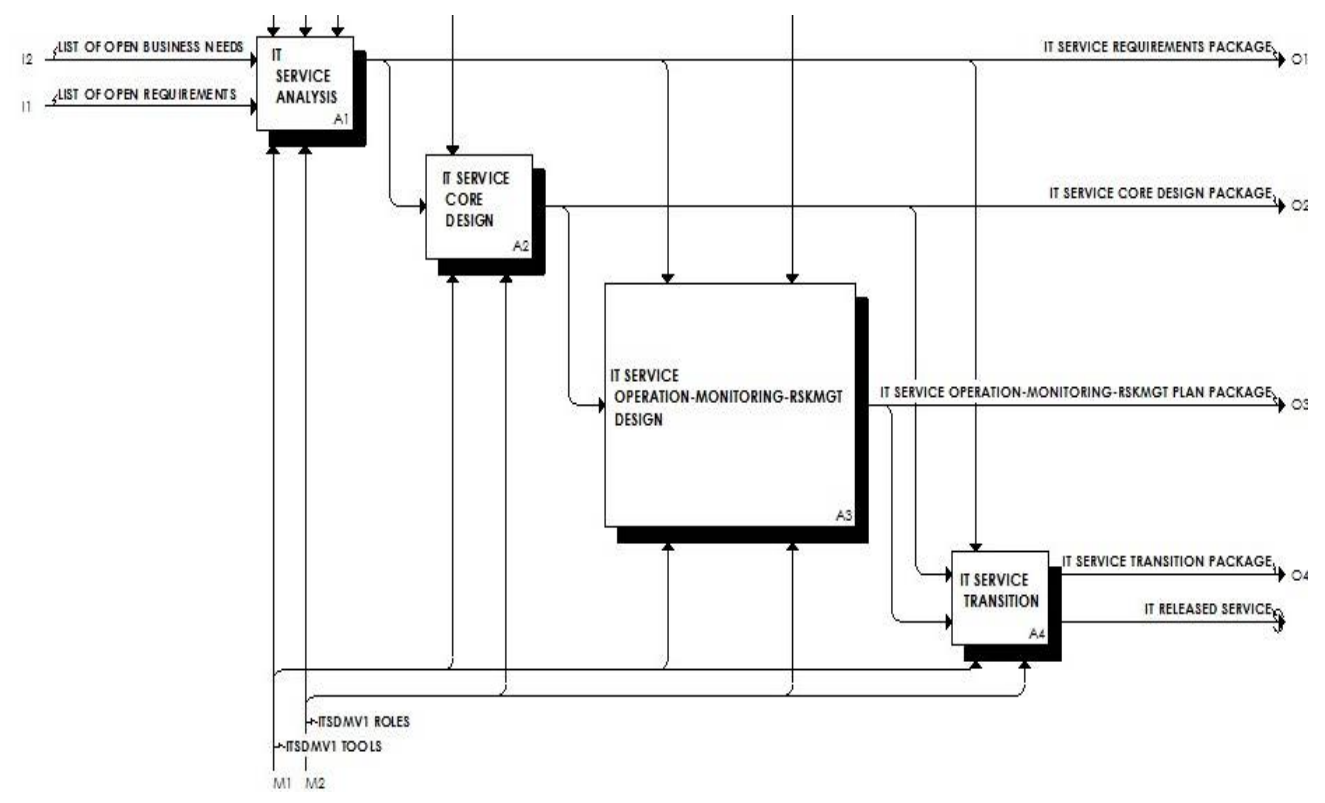

Fig. 4 The IDEF0 Diagram of ITSDM

The figure 4 shows also a fourth activity named IT Service Transition. This activity is not part of the design process but it is shown for better understandings of the next activities to be performed once complete the design of an IT service.

In the first phase of 1) IT service requirements analysis are conducted three activities: 1.1) Identification of IT service context, 1.2) Elicitation of IT service requirements, and 1.3) Validation-agreement of implementable 
IT service requirements. In the second phase of 2) IT service core design are conducted two activities: 2.1) Core design of IT service, and 2.2) Specification of IT service components. Finally, in the third phase of 3) IT service operation-monitoring-rskmgt planning are conducted two activities: IT service operation-monitoring-rskmgt planning, and service design overall authorization. These activities are performed by the following roles: IT Service Project Manager, IT Service Design Team, IT Service Customer, IT Service User, IT Service Staff, ITSM Staff and IT Service External Staff. In ITSDM are generated three general artifacts: requirements package, design package, and operation plan package. Each package contains several documents and diagrams. All of them are based on the SysML notation (OMG 2007). SysML has been recommended for designing general systems in the discipline of Systems Engineering.

The Tables 4, 5 and 6 show the general descriptors for the three ITSDM phases. Each descriptor contains the following items: purpose, roles, inputs, controls, activities, outputs and an IDEF0 diagram of activities.

Table 4 Descriptor of the Phase I in ITSDM

\section{PHASE I: IT SERVICE REQUIREMENTS ANALYSIS}

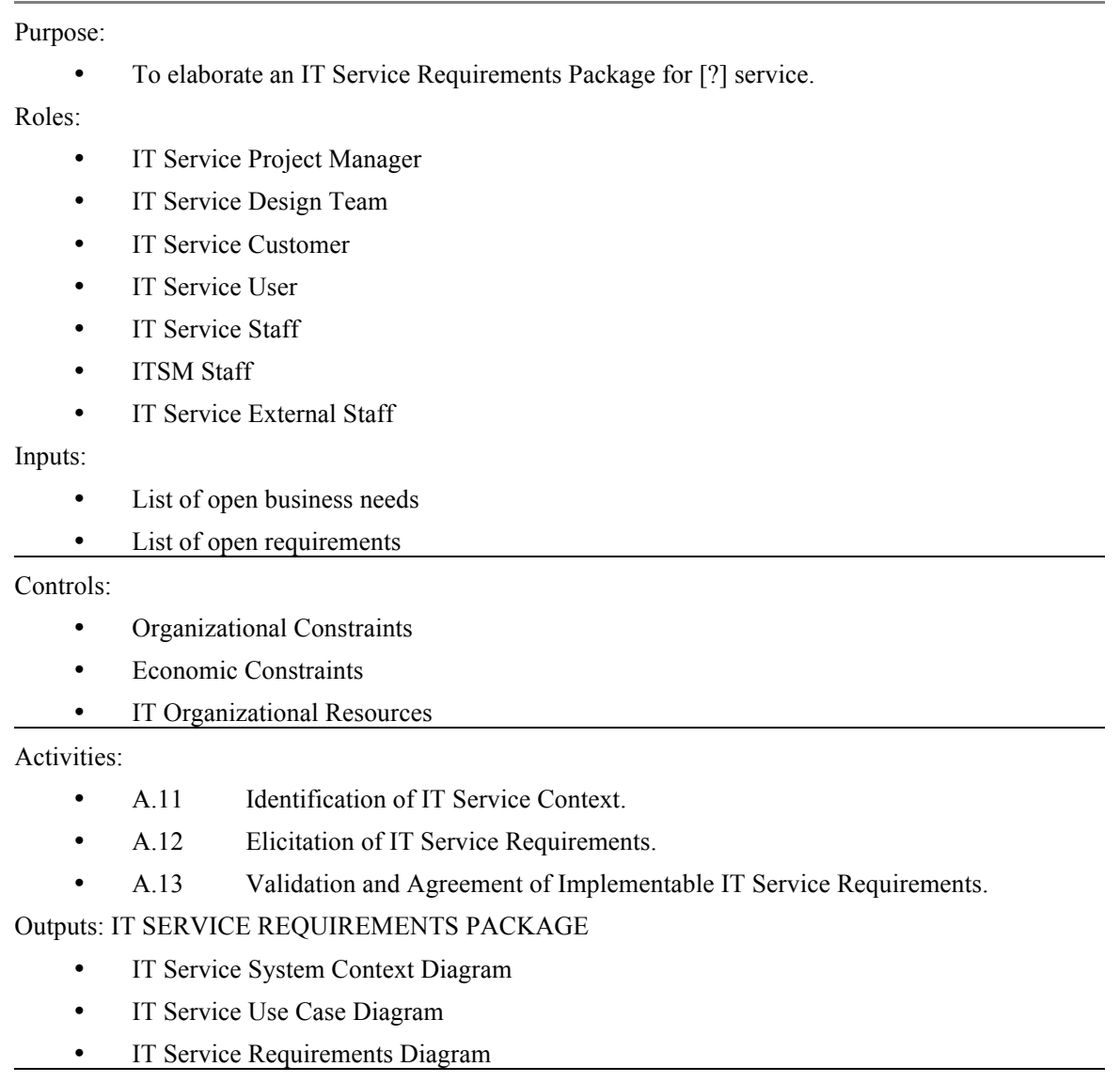

IDEF0 Diagram: 


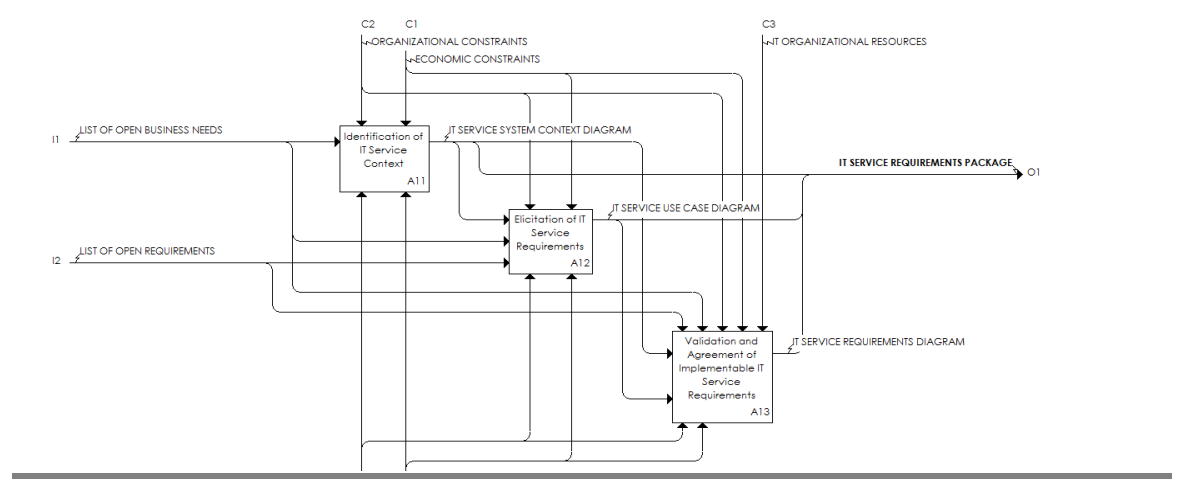

For instance, in the Table 4, the first phase of ITSDM named IT Service Requirements Analysis reports as its essential purpose to elaborate the IT Service Requirements package. This package consists basically of three artifacts: IT Service System Context Diagram, IT Service Use Case Diagram, and IT Service Requirements Diagram. The first two diagrams are widely known and used by software and systems engineers. The third artifact is used in systems engineering and uses a SysML notation (OMG 2007). The first artifact, IT Service System Context Diagram, portrays the essential four design blocks and their key stakeholders from a highest level perspective of the IT service design. These four design blocks are: the IT service block, the served business process block, the IT service system block, and the IT external service system block. These four blocks must be considered in overall in a IT service design. The omission or lack of consideration in some of them can lead a flawed design. For instance, the lack of a care design consideration of the IT external service system block such as ISP (internet service suppliers) or power energy suppliers, or IT suppliers-consulting for some critical IT resources, can lead a failed lately IT service. This Table 4 reports also the participants (in this case the seven ones), the inputs (list of open business needs, and list of open requirements), the outputs (the IT Service Requirements Package), the activities (A.11 Identification of IT Service Context, A.12 Elicitation of IT Service Requirements, and A.13 Validation and Agreement of Implementable IT Service Requirements), and an IDEF0 diagram which shows graphically the interrelationships between activities, inputs, outputs, controls and participants (called mechanisms in IDEF0)

The Tables 5 and 6 reports similar information for the next two phases of IT Service Core Design, and IT Service Operation-Monitoring-RskMgt.

Table 5 Descriptor of the Phase II in ITSDM

\section{PHASE II: IT SERVICE CORE DESIGN}

\begin{tabular}{cl}
\hline $\begin{array}{c}\text { Purpose: } \\
\bullet\end{array}$ & To elaborate an IT Service Core Design Package for [?] service. \\
\hline Roles: & \\
$\bullet$ & IT Service Project Manager \\
$\bullet$ & IT Service Design Team \\
$\bullet$ & IT Service Customer \\
$\bullet$ & IT Service User \\
$\bullet$ & IT Service Staff \\
$\bullet$ & ITSM Staff \\
\hline
\end{tabular}


IT Service External Staff

Inputs:

- $\quad$ IT Service Requirements Package

Controls:

- $\quad$ IT Organizational Resources

Activities:

- A.21 Core Design of IT Service

- $\quad$ A.22 Specification of IT Service Components

Outputs: IT SERVICE CORE DESIGN PACKAGE

- $\quad$ IT Service Design Block Diagram

- $\quad$ IT Service Component Specification Block Diagram

IDEF0 Diagram:

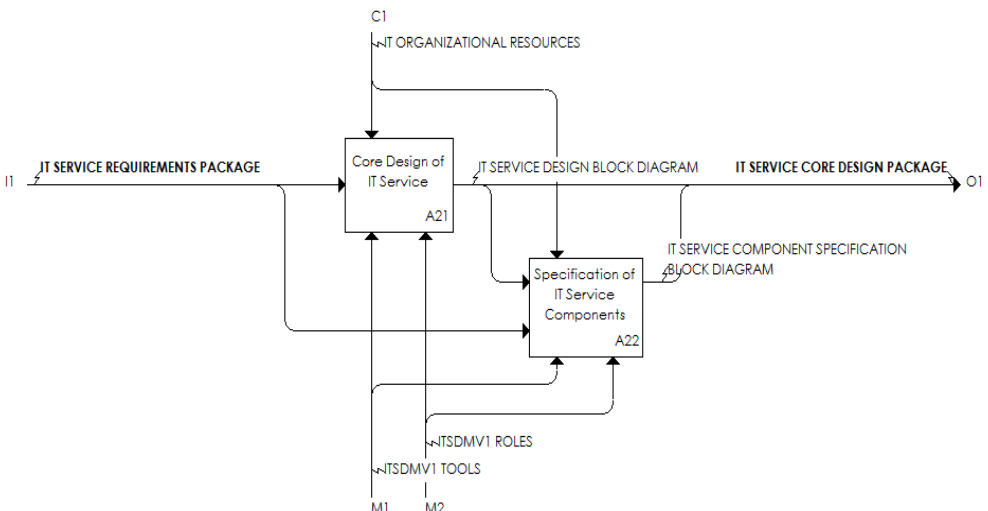

Table 6 Descriptor of the Phase III in ITSDM

\section{PHASE III: IT SERVICE OPERATION-MONITORING-RSKMGT DESIGN}

Purpose:

- To elaborate an IT Service Requirements Package for [?] service.

Roles:

- $\quad$ IT Service Project Manager

- $\quad$ IT Service Design Team

- $\quad$ IT Service Customer

- $\quad$ IT Service User

- $\quad$ IT Service Staff 


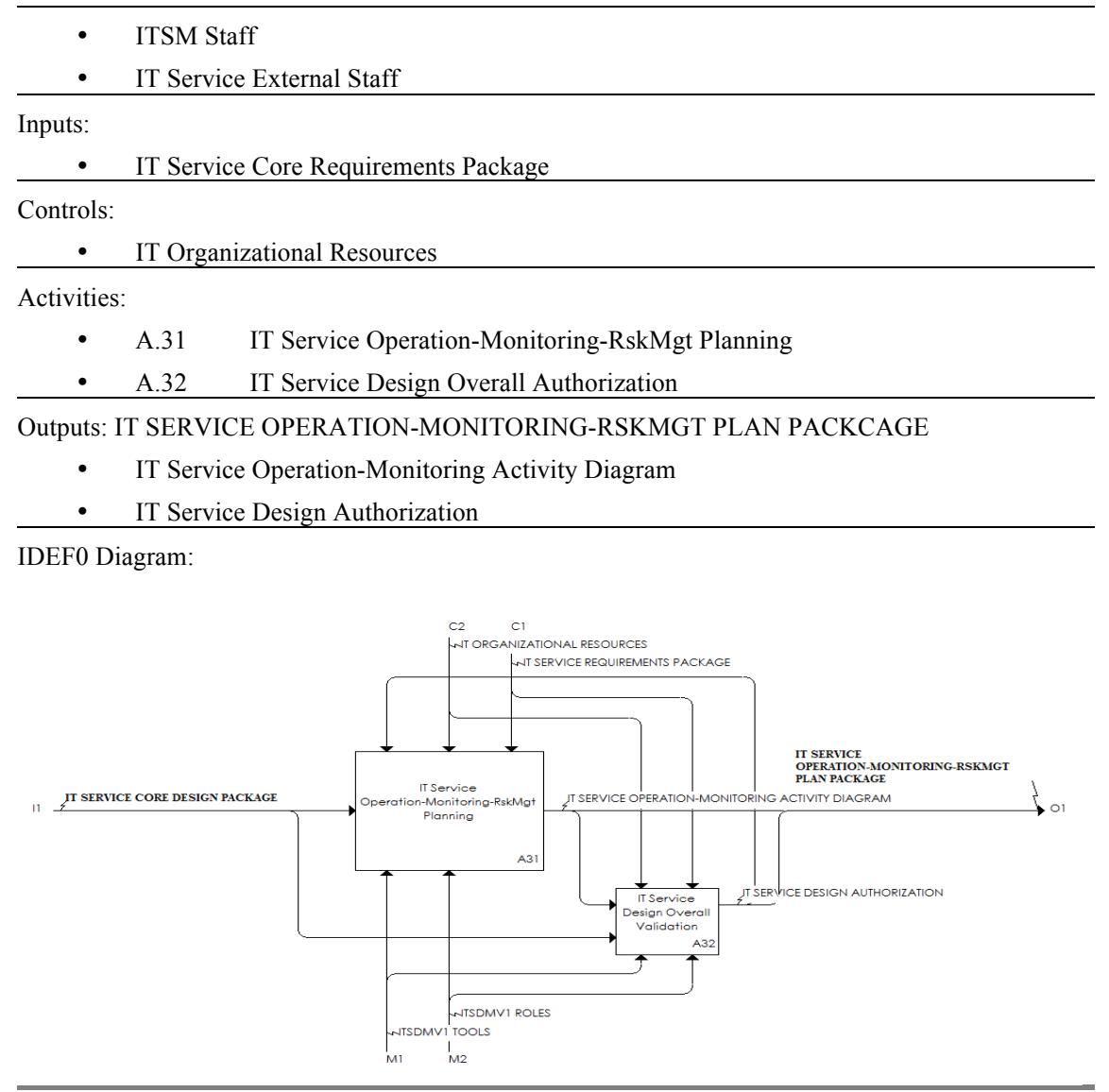

We consider that ITSDM is a step-by-step methodology because it provides well-structured descriptions for each one of the seven activities in ITSDM. The Table 7 for instance shows the step-by-step guide of the first activity A.11 Identification of IT Service Context

This descriptor contains the following elements: participants, expected duration, inputs, controls, tasks description, outputs and outputs templates. In particular, with the availability of tasks description and output templates, the design of an IT service is guided reducing ambiguity and uncertainty in what steps and what must contain an expected output.

Table 7 Descriptor of the Activity A.11 Identification of IT Service Context

Activity A.11 Identification of IT Service Context

Participants:

- ITS Customer, ITS User, ITS Project Manager, ITS Staff and ITS Design Team

Expected Duration:

- $\quad$ Small, simple or well-known IT Services: one 1-hr meeting 
- Medium-sized, moderate complexity or new IT Services: two or three 1-hr meetings

Inputs:

- List of Open Business Needs

Controls:

- Organizational Constraints

- Economic Constraints

Tasks Description:

- This is the first formal activity of ITSDM. In this activity, a meeting coordinated by the ITS Project Manager and with the participation of the ITS Customer, ITS User, ITS Staff and ITS Design Team is held.

- ITS Customer and ITS User are expected to report a set of open business needs. These ones must be specified in a \{ITS problem $\}$ and a \{served business process $\}$ descriptions.

- Based on such previous descriptions, jointly ITS Customer, ITS User, ITS Staff and ITS Design Team must delineate a general and likely \{IT service block\}.

- ITS Staff and ITS Design Team must also to elaborate the general descriptions of the related \{ITSM block\} and \{IT external service block\} that will support and deliver the expected \{IT service block\}.

- ITS Staff must also complement the descriptions of the stakeholders: ITS Customer, ITS User, ITS Staff, ITS Design Team, ITSM Staff, IT External Services Staff\}.

- Finally, it must be remarked that all descriptions realized in this activity must consider the general organizational and economic constraints reported for both parts (customer/user and technical ones).

Outputs:

- IT Service System Context Diagram.

Outputs Templates: IT Service System Context Diagram

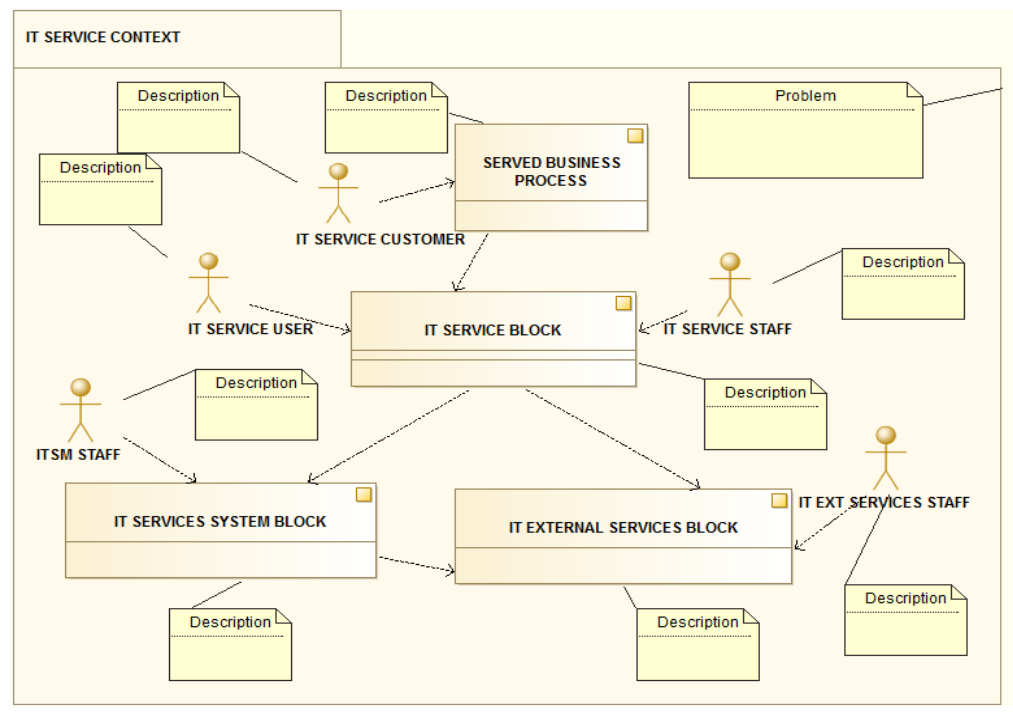




\subsection{ITSDM: Illustrative Case}

In this section we will report selective evidences on how ITSDM fits a correct IT service design process from a real IT service planned, designed, transitioned and operated currently in the University of Oldenburg. This IT service is named Cloud-Storage: your personal data storage (https://cloudstorage.uni-oldenburg.de/).

This IT service is described as follows: "The data service "cloud storage" allows you to reflect a local directory on your device to the data management system of the university and must be kept in the background sync. The synchronization works not only with one but with any number of devices, so you cannot use the data backup but also to synchronize your data between your devices the service. Additionally, you can put the synchronized folder or parts thereof decidedly individual users for reading or for writing available" (http://www.unioldenburg.de/itdienste/services/datenhaltung/cloudstorage).

In this IT service, we use a reverse engineering to test ITSDM. The IT service Cloud-Storage was already operational at the University of Oldenburg, and we tested the suitability and compatibility of ITSDM on the process followed by IT service design team at University of Oldenburg, which was reported as a mixed of process based on the best practices of ITIL V3 and ISO/IEC 20000, complemented with the ad-hoc expertise of the IT service team in this university.

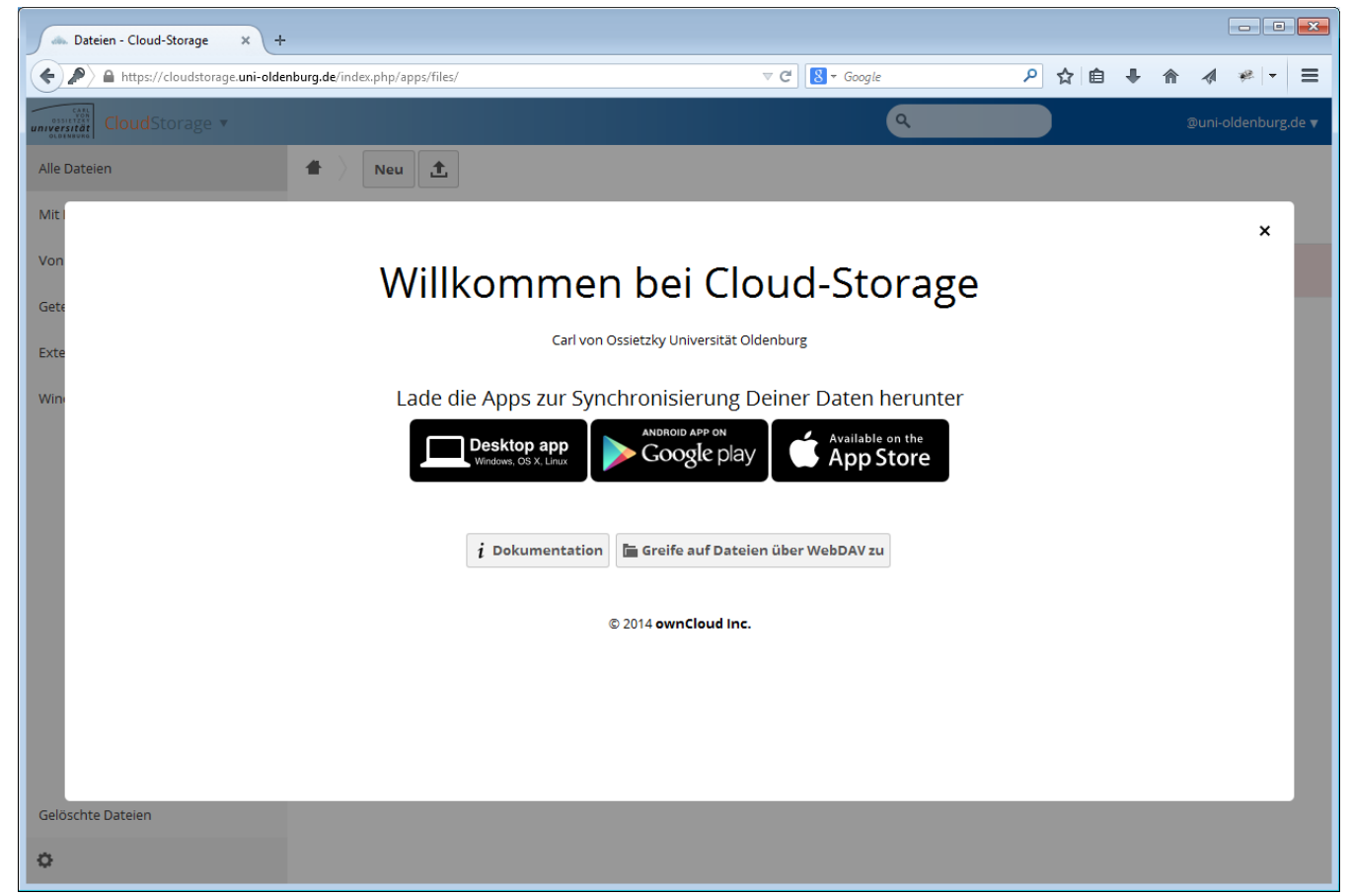

Fig. 5 Website of the IT Service Cloud-Storage at University of Oldenburg

However which is relevant for this research is the acceptance of the IT service design team on the lack of step-by-step well-structured guide for this process. Consequently, the IT service design process followed in this case was the particular interpretation of ITIL V3 and ISO/IEC 20000 recommendations and general practices. 
By space limitations, we report only some representative evidences on the application (in reverse engineering mode) of the ITSDM process for documenting and validating the design of the IT service Cloud-Storage. The figures 6 to 9 show the application of the Phase I of IT Service Analysis, and the artifacts IT Service Systems Context Diagram, IT Service Requirements Diagram, and IT Service Design Block Diagram.

In the figure 6 on the application of the Phase I of IT Service Analysis are identified (and documented) the roles (stakeholders), the inputs (list of open business needs, and list of open requirements), and the controls (organizational constraints, economic constraints, and IT organizational resources). In this particular case we can remark that the IT customer was the Vice-President of Administration, and the IT users the groups of research, academic, graduate students, undergraduate students and managerial personnel at the university. Regarding inputs, were identified the next list of open business needs: 1) research groups have national and international collaborations which demand that large quantity of data be shared in an efficient and secure mode, and 2) several groups of stakeholders (academics, graduate students, bachelor students, and management personnel), need data synchronization with their mobile devices. On list of open requirements these were the following ones: 1) to enable a web-based service of cloud-storage and backup which be secure and efficient for all stakeholders (research groups, academics, graduate students, bachelor students, and managerial personnel), and 2) this service must provide the storage service including automatic backup functionality in several SLAs according to type of stakeholder. This figure 6 shows also the main organizational and economic constraints as well as the general IT resources required for the IT service. The organizational constraint was established as: the IT service must be released in 6 months and have a useful life over 3 years. The economic constraint was established as: to design, activate and release the IT service using affordable enterprise versions of open source available platforms. The IT resources constraint was identified as: IT infrastructure will be limited to the available in the main (at main Campus) and secondary (at Wechloy Campus) data centers. 


\begin{tabular}{|c|c|}
\hline PHASE 1 & II SERVICE ANALYSIS \\
\hline Purpose & $\begin{array}{l}\text { To elaborate an IT Service Requirements Package for: CLOUD-STORAGE } \\
\text { SERVICE }\end{array}$ \\
\hline Roles & $\begin{array}{l}\text { - IT Service Project Manager: General Manager of IT Services } \\
\text { - IT Service Design Team: Data Center Manager, IT Service Design } \\
\text { Engineer } \\
\text { - IT Service Customer: Vice-president of Administration } \\
\text { - IT Service User: Research Groups, Academic Groups, Graduate } \\
\text { Students, Bachelor Students and Managerial Personnel. } \\
\text { - IT Service Staff: } 2 \text { ITS engineers } \\
\text { - ITSMStaff: } 2 \text { ITS networking engineers } \\
\text { - IT Service External Staff: DFN Services Staff }\end{array}$ \\
\hline Inputs & $\begin{array}{l}\text { - List of open business needs } \\
\text { OBN.01 Research groups have national and international } \\
\text { collaborations which demand that large quantity of data } \\
\text { be shared in an efficient and secure mode. } \\
\text { OBN.02 Several groups of stakeholders (Academics, } \\
\text { Graduate Students, Bachelor Students, and Management } \\
\text { Personnel), need data synchronization with their mobile } \\
\text { devices. } \\
\text { - List of open requirements } \\
\text { OR.01 To enable a web-based service of CLOUD STORAGE } \\
\text { AND BACKUP which be secure and efficient for all } \\
\text { stakeholders (Research groups, Academics, Graduate } \\
\text { Students, Bachelor Students, and Managerial Personnel). } \\
\text { OR.02 This service must provide the storage service } \\
\text { including automatic backup functionality in several SLAs } \\
\text { according to type of stakeholder. }\end{array}$ \\
\hline Controls & $\begin{array}{l}\text { - Organizational Constraints } \\
\text { OC. } 01 \text { The IT service must be released in } 6 \text { months and have } \\
\text { a useful life over } 3 \text { years. } \\
\text { - Economic Constraints } \\
\text { EC. } 01 \text { To design, activate and release the IT service using } \\
\text { affordable enterprise versions of open source available } \\
\text { platforms. } \\
\text { - IT Organizational Resources } \\
\text { ITOR.01 IT infrastructure will be limited to the available in the } \\
\text { main (at main Campus) and secondary (at Wechloy } \\
\text { Campus) data centers. }\end{array}$ \\
\hline
\end{tabular}

Fig. 6 Application of Phase I of ITSDM for the IT Service Cloud-Storage at the University of Oldenburg 


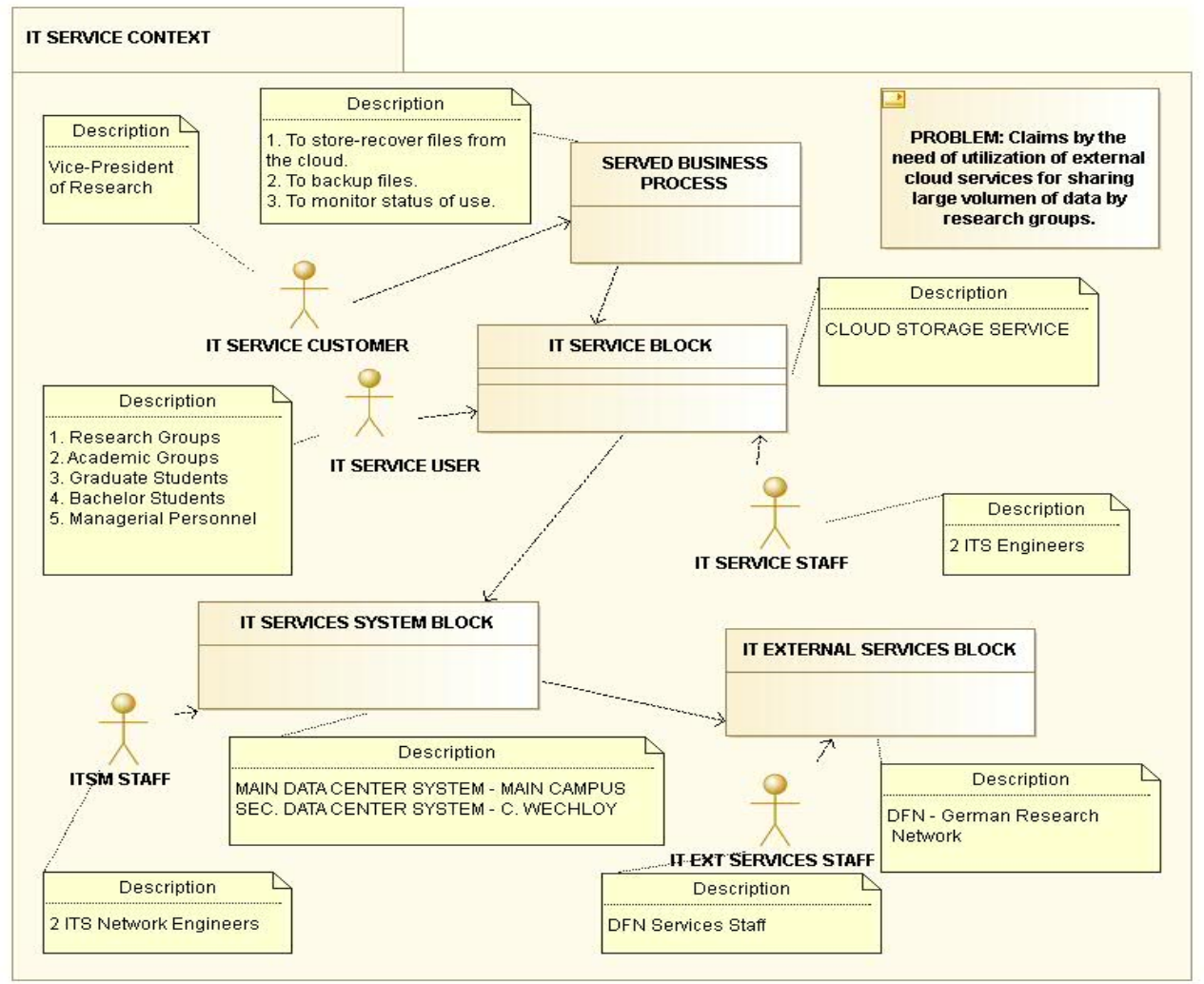

Fig. 7 Application of Phase I of ITSDM for the IT Service Cloud-Storage at the University of Oldenburg - IT Service System Context Diagram Output

In the figure 7 is shown the artifact IT Service Systems Context Diagram. This diagram is useful to highlight the four essential design blocks for an IT service, their stakeholders and additional relevant information, in a single 1-page document. The figure 7 shows for instance, that the IT service Cloud-Storage addresses the problem of claims of relevant groups of users at the University of Oldenburg (mainly research teams) by the need of using external and free but limited services of cloud for data storage. It reports also the IT service customer as the Vice-President of Administration, and the IT service users. Other important design block identified is the IT external service system which is in this case the DFN (German Research Network). This external system is critical given it provides the network internet connectivity among the two campus of the University of Oldenburg, and the group of German research and academic institutions, and lately the global internet connectivity. 


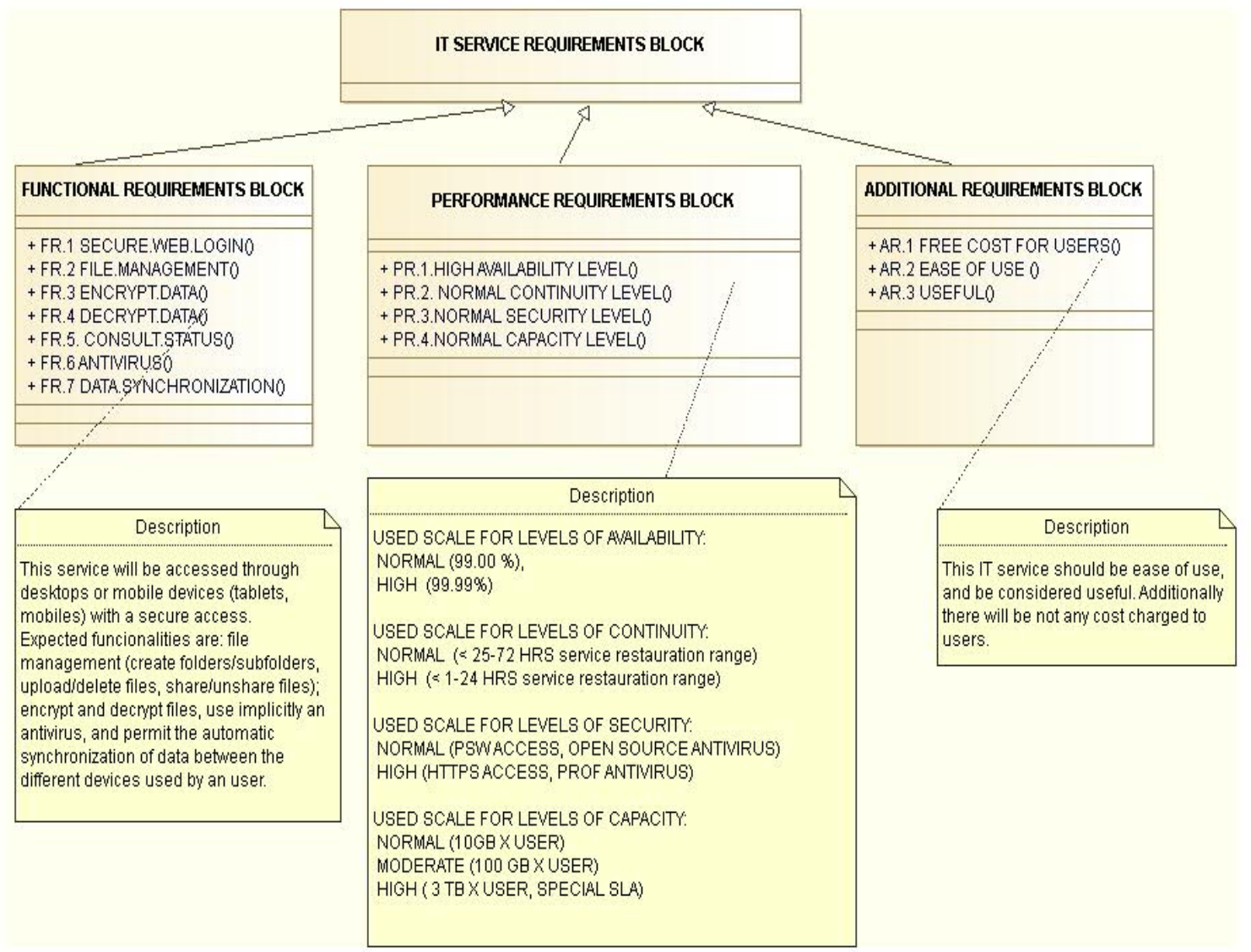

Fig. 8 Application of Phase I of ITSDM for the IT Service Cloud-Storage at the University of Oldenburg - IT Service Requirements Diagram Output

In the figure 8 is shown the artifact IT Service Requirements Diagram. This diagram is useful to agree the expected levels of quality of service classified in functional, performance and other ones. Among the main functional requirements asked are the following ones: 1) a secure login, 2) encryption of data, and 3) automatic antivirus service. Regarding to performance requirements, the ITSDM proposes the utilization of at least the four ITIL V3 metrics of value (i.e. the warranty dimension) on availability, continuity, security and capacity. In this particular real case the IT service Cloud-Storage was agreed with a high availability level, and normal levels for the remainder three warranty metrics. Regarding other requirements classification it was established: 1) a free cost access of the IT service for all group of users, and 2) ease of use. This IT Service Requirements Diagram also includes brief but substantial descriptions of each group of requirements. 


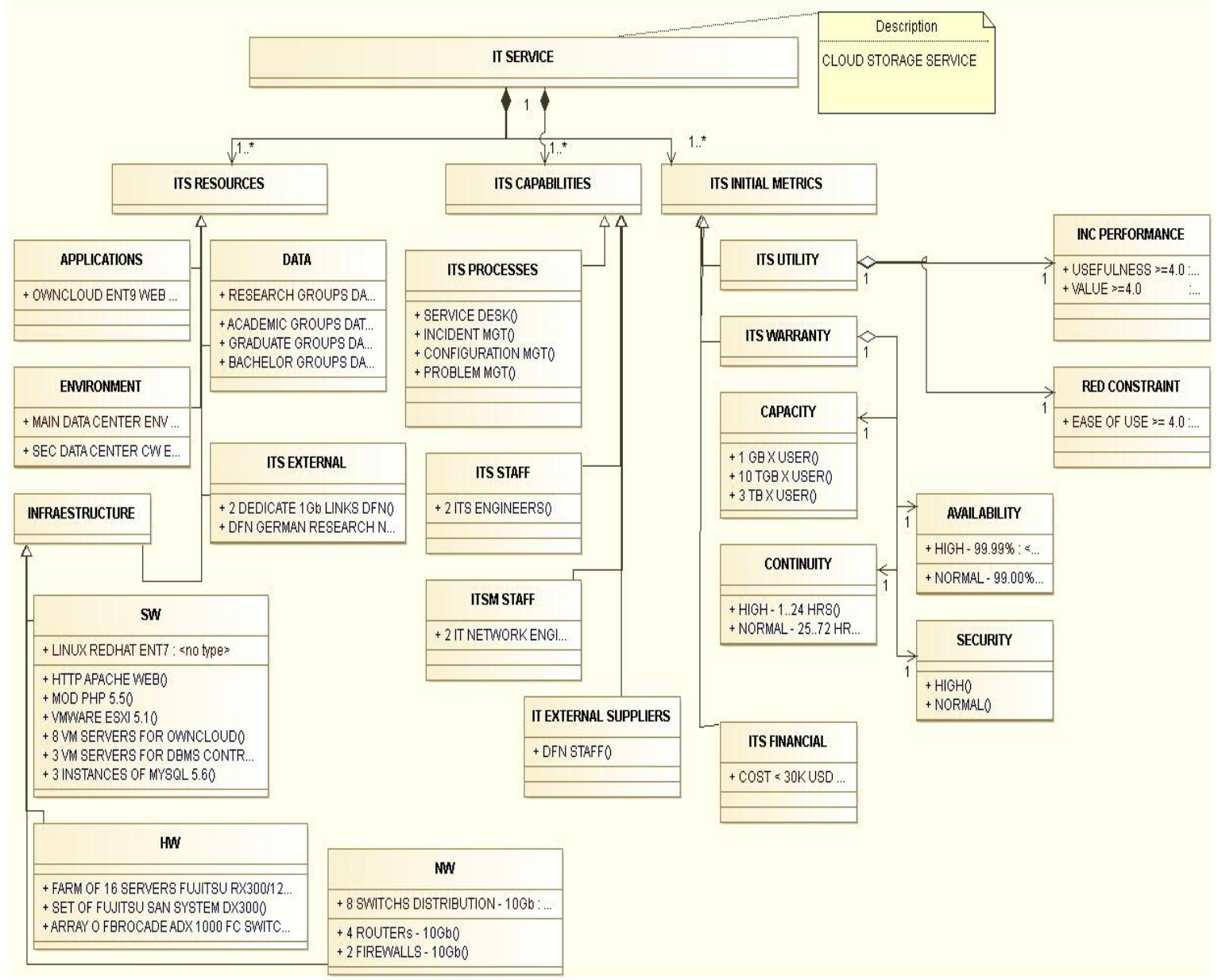

Fig. 9 Application of Phase I of ITSDM for the IT Service Cloud-Storage at the University of Oldenburg - IT Service Design Block Diagram Output

In the last figure 9 the IT Service Design Block Diagram reports the structure essential of the IT service with three set of components: 1) IT service resources (applications, data, infrastructure (hardware, software, network), environment, and external services); 2) IT service capabilities (processes, service staff, service system staff, external staff); and IT service initial metrics (utility and warranty ones).

Each element reports the essential but relevant data associated to such elements. For instance for hardware in the IT service resources category were identified the following specific resources: 1) a sever farm of 16 servers Fujitsu PRIMERGY RX300 S8 Dual-Socket Rack-Server (2 HE), 12 cores, 64GB RAM, 15TB virtual disk; 2) set of Fujitsu SAN with a 1 Petabyte of storage; 3) an array of FC Brocade switches for the SAN. For software also in the IT service resources category were identified the following resources: 1) OS Linux Enterprise 7; 2) HTTP Apache web servers; 3) PHP v.5.5; 4) VMWare ESXI 5.1; 5) eight VM servers for OwnCloud Enterprise Application; 6) three VM servers for DBMS services; and 7) three instances of MySQL 5.6. Regarding to the application type also in the IT service resource category, the unique element identified was OwnCloud Enterprise ver- 
sion 9.0. Other critical element is IT external services in the IT service resource category and in this case were identified two ones: 1) two dedicated X-WiN-links of $1 \mathrm{Gbit} / \mathrm{s}$ each one.

The figure 9 also includes the identification of the IT service capabilities regarding processes, service staff, service system staff, and external services staff. In this case, the processes agreed to be implemented for supporting this IT service of Cloud-Storage were the following ones: Service Desk, Incident Management, Configuration Management, and Problem Management. On the service staff dedicated to this particular service were assigned two IT engineers. It must be remarked that these staff also is responsible of other IT services.

Finally, this figure 9 (i.e. the IT Service Design Block Diagram) shows the essential information agreed on IT service metrics: utility and warranty. On utility metrics were established: 1) to increment performance of users measured by perceived value and usefulness from users by using a Likert scale from 1 (very low score) to 5 (very high score); and 2) reduce difficult of utilization of users measured by ease of use with a similar Liker scale from 1 to 5 points. On warranty, several specific metrics were established also for the four dimensions (availability, continuity, security and capacity). An additional category of IT service metrics was added: IT service financial ones. It was established as a total investment for deploying this IT service on at most 30,000 euros.

Hence, this section has presented evidences of the utilization of ITSDM (in reverse engineering mode) for documenting and testing the applicability for designing a real IT service in an organization. In this particular illustrative real case, the IT service considered was a Cloud-Storage service deployed already operational at the University of Oldenburg, Germany. This IT service was planned, designed, built and operated by the IT Service Department of the University of Oldenburg, managed by the fourth co-author of this chapter.

This documentation process was conducted during three interviews by first two co-authors with the IT Service manager, the IT Data Center manager, and one IT principal IT service engineer from the University of Oldenburg, Germany during July 2016, in a research stay from first author. Second and third co-authors reviewed the application of the ITSDM methodology and provide valuable insights for the elaboration of this chapter.

Finally, a quantitative final evaluation was not possible by time restrictions but several positive comments were collected from the IT service team. In overall, they considered the ITSDM methodology as: 1) theoretically well supported from the best ITSM schemes such as ITIL V3 and ISO/IEC 20000; 2) very adequate for the purpose of designing and documenting a new IT service; 3) ease of use; 4) useful; and 5) with interest to be used (with adaptations) in future IT service designs.

\section{Conclusions}

In this chapter, we have presented a new IT service design methodology named ITSDM. It has emerged from the recommendations from best practices schemes such as ITIL V3 and ISO/IEC 200000. It was motivated for the lack of well-structured step-by-step guides for designing an IT service. ITDSM consists of three phases (IT Service Analysis, IT Service Core Design, and IT Service Operation-Monitoring-RskMgt) and it provides a set of activities, tasks, roles, inputs, controls, and outputs artifacts with specific templates. It considers and it is theoretically compatible with ITIL V3 and ISO/IEC 20000 terminology and conceptual schemes.

ITDSM was tested in a reverse engineering mode for a real IT service implemented in a German university: a Cloud-Storage service. ITSDM was applied for documenting the IT service Cloud-Storage service ((https://cloudstorage.uni-oldenburg.de), through three interviews with IT service department people and research team. We found that ITSDM was capable of including all critical IT service design elements already considered by the IT service department in the German university, and was considered, in overall, as useful and ease of use. 
Hence, this chapter provides initial evidence of the usefulness of ITSDM and proposes additional empirical studies for improving it. Given the lack of well-structured and step-by-step IT service design methodologies in the worldwide arena, we consider that ITSDM is a forward step in this direction.

\section{Acknowledgements}

This research was developed with the financial support of the Autonomous University of Aguascalientes, Mexico (www.uaa.mx) (Project PIINF08-2).

\section{References}

Cartlidge, A. (2007). An Introductory Overview of ITIL ${ }^{\circledR}$ V3, Zaltbommel, The Netherlands: Van Haren.

Cater-Steel, A. and Toleman, M. (2006). Transforming IT Service Management - the ITIL Impact. In: Proceedings of the 17th Australasian Conference on Information Systems, Adelaide, Australia, December 6-8, 1-11.

Cater-Steel, A., Toleman, M., and Wui-Gee, T. (2009). itSMF Australia 2009 Conference: Summary Report of ITSM Standards and Frameworks Survey. In: Proceedings itSMF Australia 2009 Conference, Adelaide, Australia, December 6-8, 1-16.

Curtis, B., Kellner, M., and Over, J. (1992). Process Modeling. Communications of the ACM, 35(9), 75-90

Ebert, N., Uebernickel, F., Hochstein, A. and Brenner, W. (2007). A Service Model for the Development of Management Systems for IT-enabled Services. AMCIS Conference, Colorado, USA, August 9-12, 1-8

Gallup, S., Dattero, R., Quan, J., and Conger, S. (2009). An Overview of IT Service Management. Communications of the ACM, 52(5), 124-127.

Glass, R., Armes, V., and Vessey, I. (2004). An analysis of research in computing disciplines. Communications of the ACM, 47(6), 89-94.

Hevner, A. R., March, S. T., Park, J., and Ram, S.(2004). Design science in information systems research. Management Information Systems Quarterly, 28(1), 75-105.

Hochstein, A., Tamm, G., and Brenner, W. (2005). Service Oriented IT Management: Benefit, Cost and Success Factors. In: Proceedings of the ECIS 2005, Paper 98, http://aisel.aisnet.org/ecis2005/98.

INCOSE (2004). Systems Engineering Handbook. INCOSE-TP-2003-016-02. Internet document at www.incose.org

ISO. (2005). ISO/IEC 20000-1 Information Technology - Service Management Part 1 Specification. Geneva, Switzerland: ISO.

ISO. (2007). ISO/IEC 15288: Systems Engineering - Systems Life Cycle Processes -. ISO/IEC, Geneva, Switzerland.

ISO. (2010). ISO/IEC 20000-4 Information Technology - Service Management Part 4 Process Reference Model. Geneva, Switzerland: ISO.

Johnson, M., Hately, A., Miller, B., and Orr, R. (2007). Evolving standards for IT service Management. IBM Systems Journal, 46(3), 583-597.

Maier, M., Emery, D., \& Hilliard, R. (2004). ANSI/IEEE 1471 and Systems Engineering. Systems Engineering, 7(3), 257-270

March, S., and Smith, G. (1995). Design and Natural Science Research on Information Technology. Decision Support Systems, $15(4), 251-266$

Mayer, R.J. (1992). IDEFO Function Modeling - A Reconstruction of the Original Air Force Wright Aeronautical Laboratory Technical Report - AFWAL-TR-81-4023. Knowledge-Based Systems, Inc., College Station, TX.

Mora, M., Gelman, O., Paradice, D., and Cervantes, F. (2008). The case for conceptual research in information systems. In: $e$ Proceedings of the International Conference on Information Resources Management, Niagara Falls, ON, Canada, May 18-20, (pp. 1-10).

Mora, M., O'Connor, R., Raisinghani, M., and Macías-Luévano, J. (2011). An IT service engineering and management framework (ITS-EMF). International Journal of Service Science, Management, Engineering, and Technology, 2(2), 1-15.

Mora, M., Raisinghani, M., and Gelman, O. (2012). A Comparison of Service Design Processes in Relevant International ITSM Models and Standards. In: Proceedings of the SIGSVC Worksop, Pre-ICIS Conference, Phonix, AZ. All Sprouts Content. Paper 516. http://aisel.aisnet.org/sprouts_all/516.

Mora, M., Raisinghani, M., O'Connor, R., Marx-Gomez, J., and Gelman, O. (2014). An extensive review of IT service design in seven international ITSM processes frameworks: Part I. International Journal of Information Technologies and Systems Approach, 7(2), 83-107. 
Mora, M., Marx-Gomez, J., O'Connor, R. V., Raisinghani, M., and Gelman, O. (2015). An Extensive Review of IT Service Design in Seven International ITSM Processes Frameworks: Part II. International Journal of Information Technologies and Systems Approach, 8(1), 69-90.

Potgetier, B., Botha, J., and Lew, C. (2005). Evidence that use of the ITIL framework is effective. In: Proceedings of the 18th Annual Conference of the National Advisory Committee on Computing Qualifications, Tauranga, NZ, 2005, 160-167.

Presley, A., and Liles, D. H. (1995). The Use of IDEF0 for the Design and Specification of Methodologies. In: Proceedings of the 4th Industrial Engineering Research Conference.

OGC. (2007). Glossary of ITIL ${ }^{\circledR}$ V3 Terms and Acronyms. FGI, Internet Document.

OMG (2007). Systems Modeling Language Specification (SysML), Object Management Group, internet document at: http://www.omg.org/spec/SysML/1.4/PDF/

Rudd, C., and Lloyd, V. (2007). ITIL Version 3 Service Design. London, UK: The Stationery Office.

Sage, A. (2000). Systems Engineering Education. IEEE TSMC Part C, 30(2), 164-174.

van Bon, J., De Jong, A., Kolthof, A., Pieper, M., Tjassing, R., van der Veen, A., and Verheijen, T. (2010). Foundations of IT Service Management Based on ITIL $\mathbb{8} v 3$, Zaltbommel, The Netherlands:Van Haren, $5^{\text {th }}$ edition.

Weist, P. (2009). An AHP-based Decision Making Framework for IT Service Design. In: MWAIS 2009 Proceedings, Paper 11, http://aisel.aisnet.org/mwais2009/11 
Dr. Manuel Mora is a full-time Professor-Researcher and Coordinator of the CONACYT-PNPC MSc on IT program in the Information Systems Department at the Autonomous University of Aguascalientes (UAA), Mexico. Dr. Mora holds a B.S. in Computer Systems Engineering (1984) and a M.Sc. in Computer Sciences (Artificial Intelligence area, 1989) from Monterrey Tech (ITESM), and an Eng.D. in Engineering (Systems Engineering area, 2003) from the National Autonomous University of Mexico (UNAM). He has published over 90 research papers in international top conferences, research books, and refereed journals listed in JCRs such as IEEE-TSMC, European Journal of Operational Research, Int. Journal of Information Management, Engineering Management, Int. J. of Information Technology and Decision Making, Information Technology for Development, Int. J. in Software Engineering and Knowledge Engineering, and Computer Standards \& Interface. Dr. Mora is a senior member of ACM (since 2008), of IEEE SMC Society, of INCOSE, and of the Mexican National Research System at Level I, and serves in the ERB of several international journals indexed by Emergent Source Citation Index focused on decisionmaking support systems (DMSS) and IT services systems. Dr. Mora has co-edited also four international research books in the topics of DMSS, IT services and Research Methods for prestigious academic publishers like Springer and IGI.

Jorge Marx Gómez is a full-time professor of Business Information Systems at the Carl von Ossietzky University Oldenburg, Germany since 2005. He holds a B. in Computer Engineering and Industrial Engineering at the University of Applied Science of Berlin (Technische Fachhochschule), and a Ph.D. degree in Business Information from Otto-von-Guericke-Universität Magdeburg. In 2004 he received his habilitation for the work Automated Environmental Reporting through Material Flow Networks at the Otto-von-Guericke-Universität Magdeburg. From 2002 till 2003 he was a Visiting Professor for Business Information Systems at the Technical University of Clausthal. Currently, Dr. Marx Gómez is the head of the department Business Informatics (Very Large Business Applications). His personal research interests include Environmental Management Information Systems, Business Intelligence, Material Flow Management Systems, Federated ERP-Systems, Enterprise Systems Engineering, Business Information Systems in Higher Education, Enterprise Tomography, Environmental Data Warehousing, Recycling Program Planning, Disassembly Planning and Control and Life Cycle Assessment. Dr. Marx Gómez is a member of: German Association of Computer Science (Gesellschaft für Informatik e.V., in short GI), OFFIS e.V. (Oldenburg Institute of Informatics), SAP Roundtable for Business Intelligence, German Association of University Professors and Lecturers (Deutscher Hochschulverband, in short DHV), German Forum of Interoperability (in short DFI), German Oracle Users Group e.V. (in short DOAG) and reviewer and expert in DAAD selection committee for Latin-American research proposals.

Prof. Rory V. O'Connor is a Professor of Software Engineering at Dublin City University (Ireland) and a Senior Researcher with Lero, the Irish Software Research Centre. He is Ireland's Head of Delegation to the International Organization for Standardization (ISO) for Software \& Systems Engineering (ISO/IEC JCT1/ SC7). He is also editor in chief of the journal Computer Standards and Interfaces. His research interests are centered on the processes and standards whereby software intensive systems are designed, implemented and managed. His website address: http://www.roryoconnor.com

Burkard Meyendriesch is the Manager of the IT Service Department at the University of Oldenburg, Germany. He is a senior manager with over 25 years of IT responsibilities in different organizations in Germany. 